\title{
Appearance of Resistance during Prolonged Treatment of Leprosy with Thiambutosine
}

\author{
J. M. B. GARROD, м.в., CH.B., D.т.м. \& н.* \\ G. A. ELLARD, PH.D. $\dagger$ \\ East African Leprosy Research Centre, Busia, Tororo, Uganda
}

\section{INTRODUCTION}

Earlier reports have demonstrated the efficacy of oral thiambutosine (1-(p-Dimethylaminophenyl)-3-(p-butoxyphenyl)-2-thiourea, CIBA 1906 or DFT) in the treatment of leprosy when administered for periods of between 2 and $2 \frac{1}{2}$ years (Davey et al., 1958; Garrod, 1959). There is evidence, however, that if treatment is continued beyond this time, patients may suffer clinical and bacteriological relapse. Thus, while Davey et al. (1958) found no sign of drug resistance in 12 patients who had been treated for up to 32 months with thiambutosine, between the 36 th and 44th month of treatment there was evidence that progress had halted in 6 patients with the reappearance in each patient of bacilli of normal morphology, and in 2 patients an eruption of fresh skin lesions (Davey, 1960).

This paper presents evidence of clinical and bacteriological relapse of $2(1156 / 4$ and $6203 / 36)$ of the 23 patients who had participated in the 24-month clinical trial of oral thiambutosine described earlier (Garrod, 1959) and who were then treated for a further 2 to 21 months with the drug. There was also evidence indicating the failure of another patient $(6280 / 51)$ to respond normally during the first 2 years' treatment with thiambutosine.

While these clinical and bacteriological studies were being undertaken, the absorption and metabolism of thiambutosine were being investigated in the same group of patients. Neither the clinician nor the biochemist was aware of the details of each other's findings until the conclusion of these studies. By good fortune the absorption and metabolism of thiambutosine was studied in one of the patients (1156/4) at the very time that he was beginning to show signs of clinical and bacteriological relapse.

\section{METHODS}

Smears were taken on alternative months from 6 sites, their positivity graded as $0,1,2,3$ or 4 and the average calculated as a Bacillary Index (B.I.). The absorption of thiambutosine was estimated by measuring the urinary excretion of the drug and its metabolites, using the colorimetric and radioactive methods described previously (Ellard, 1961; Ellard and Naylor, 1961).

\section{RESULTS}

\section{Clinical and Bacteriological}

Patient $1156 / 4$, a male aged about 35 years, had a history of nodular lepromatous leprosy of 7 years duration. He had proved intolerant to treatment with DDS. His B.I. at the commencement of treatment with thiambutosine was 1.7 and his Mitsuda reaction negative. A skin biopsy confirmed the clinical diagnosis. A daily dose of $3 \mathrm{gm}$. thiambutosine was administered for 15 months when persistent erythema nodosum leprosum with arthritis occurred. This was relieved with prednisone and by reducing the daily dose of thaimbutosine to $1 \mathrm{gm}$. for 2 weeks. The dose of thiambutosine was increased over the next 5 months to $3 \mathrm{gm}$. a day according to the patient's response and maintained at this level for a further 24 months, making a total of 45 months' treatment with thiambutosine. By the 19th month the B.I. had fallen to 0.3 , by the 23 rd to 0.17 and it was negative during the 28th and 29 th months. At this time the only visible evidence of leprosy was a

* Present address: 57 Attimore Road, Welwyn Garden City, Herts.

$\dagger$ Present address: MRC Unit for Research on Drug Sensitivity in Tuberculosis, Postgraduate Medical School, Ducane Road, London, W.12. 
coppery appearance to his back. All nodules had disappeared from his face and forehead and except for some looseness of the skin his face was apparently normal. By the 32nd month even the coppery tinge on his back had dizappeared but the B.I. had risen to 1.0 , although few intact bacilli were visible. His B.I. fluctuated between 1.0 and 0.5 until the $43 \mathrm{rd}$ month when it rose to 1.16 and in the 44 th month to 1.3. By the 34 th month the possibility of resistance to thiambutosine was considered as, in addition to the rise in the B.I., his face had become slightly puffy and the skin infiltrated. By the 45th month the infiltration could no longer be disregarded. At this time a nodule on his forehead, slightly to the right of the centre line, had definitely reappeared, together with another on his right mid-finger. Skin biopsies taken during the 11 th, 20th and 33rd months had indicated that he was responding satisfactorily to treatment with thiambutosine. The third biopsy was almost normal, with insufficient infiltration present to enable Ridley's Biopsy Index to be estimated (Ridley, 1958). However, by the 46th month bacilli were again very plentiful and the Biopsy Index had risen to $6(1.0 \times 6)$.

It was therefore concluded that relapse had occurred in this patient due to the appearance of strains of $M$. leprae resistant to thiambutosine. His treatment was therefore changed to DDS (dapsone).

The second patient $(6203 / 36)$ was a young female in her teens with untreated lepromatous leprosy believed to have started 5 years previously Her initial B.I. was 3.7 and her Mitsuda reaction negative. Treatment with thiambutosine was commenced at a dose of $1.5 \mathrm{gm}$. daily. After 6 months the daily dose was roised to $2 \mathrm{gm}$. until the $25 \mathrm{th}$ month when the dose was reduced to $1.5 \mathrm{gm}$. a day as it was suspected that she was starting a lepra reaction. By the 28th month new lesions were appearing and it was apparent that she was no longer responding to treatment. By the 18 th month her B.I. had fallen to 2.16 and it remained at this level until the 25th month when it had risen to 2.5. The initial diagnosis of lepromatous leprosy had been supported by a skin biopsy showing a Ridley's Index of $2.75(0.5 \times 5.5)$. By the 9th month her Biopsy Index had fallen to O.5, and by the 17 th month to 0.05. However, it was O.l at the 23rd month and had risen to 0.4 $(0.1 \times 4)$ by the 30 th month. This last biopsy confirmed the reappearance of bacilli in large numbers. It was therefore concluded that this patient had relapsed during continued treatment with thiambutosine, and she was accordingly transferred to treatment with DDS without mishap.

The third patient $(6280 / 51)$, a male aged 22 years, absorbed thiambutosine particularly poorly. He had received no previous treatment. His initial B.I. was 3.7 and his Mitsuda reaction was negative. $\mathrm{He}$ received $2.5 \mathrm{gm}$. oral thiambutosine daily for 33 months. By the 12 th month his B.I. had only fallen to 3.0 and by the 26 th month to 2.8. Progress was slower than for the other lepromatous patients treated with thiambutosine (average B.I's initially 3.2, after 12 months 2.0, and after 24 months 1.6 (Garrod, 1959)). Although clinical progress was slow it was significant. However, by the $33 \mathrm{rd}$ month progress had definitely stopped and the infiltration of his face appeared to be more marked. An old lesion on the trunk was also becoming more obvious. The initial assessment and diagnosis was supported by a skin biopsy and further biopsies carried out in the llth, 13th and 25th months confirmed his slow response to treatment. Although in this case the initial response was very poor, the clinical evidence did suggest that this patient could also have relapsed after prolonged treatment with the drug.

As it had been established that this patient was absorbing unusually small amounts of thiambutosine, he was accordingly transferred for a short period to treatment with injectable thiambutosine, and eventually to treatment with oral DISS.

TABLE

Excretion 'Total Diphenyl Thioureas' (mg.)

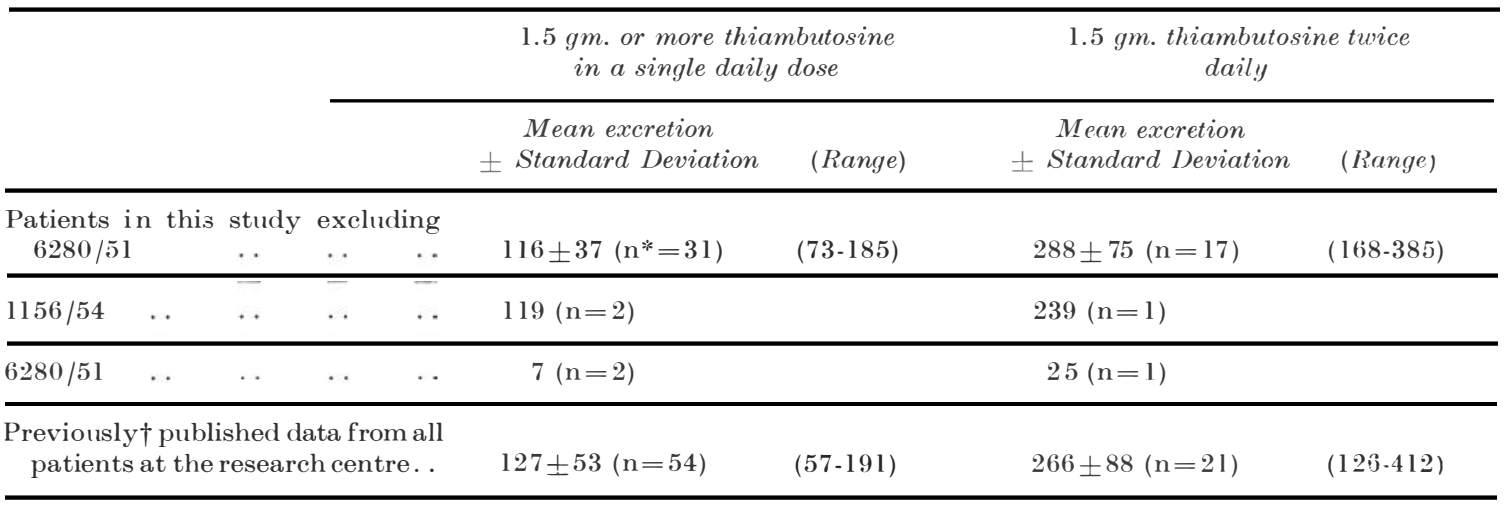

$* \mathrm{n}=$ total number of determinations

$\dagger$ Ellard (1961)

\section{Leprosy Review}




\section{Biochemical}

The results obtained using the colorimetric method are shown in the Table. The absorption of thiambutosine was measured in 15 of the 22 patients who responded satisfactorily during the first 24 months' treatment with oral thiambutosine. In these patients the absorption of thiambutosine was normal. These findings were confirmed in 3 patients by radioactive studies using ${ }^{35} \mathrm{~S}$-labelled thiambutosine (Subjects 1-3 in Experiment 1 of Ellard and Naylor, 1961).

Of the 2 patients described here, who initially responded to treatment in a satisfactory manner but on prolonged treatment subsequently relapsed, one (1156/4) was in the group studied and shown to absorb the drug normally (see Table) and this was also confirmed by radioactive technique (Subject 2, Experiment 1 of Ellard and Naylor, 1961). Hence there is definite proof that the relapse of this patient, while undergoing treatment with thiambutosine, could not have been due to unusually low absorption of the drug. The other patient who relapsed $(6203 / 36)$ also excreted normal amounts of thiambutosine and its metabolites in the urine after oral dosage. However, a detailed study of her absorption of the drug was not undertaken.

The absorption of oral thiambutosine by the third patient $(6280 / 51)$ was, however, abnormally low. The excretion of thiambutosine and its metabolites was about a tenth of the normal amount, indicating that only about $1 \%$ of the dose was being absorbed (see Table). These investigations were repeated 3 times during a period of a year with similar results and were confirmed by radioactive studies using ${ }^{35} \mathrm{~S}$-labelled thiambutosine. He was then treated by intramuscular injection with an aqueous suspension of thiambutosine and normal amounts of the drug and its metabolites were excreted in the urine (Patient 3, Table 1 in Ellard, 1966). This demonstrated that thiambutosine was being metabolised normally. After subsequent transfer to treatment with oral DDS, it was shown that he absorbed DDS normally.

\section{DISCUSSION}

Definite clinical and bacteriological evidence of relapse was obtained in 2 patients and there were indications of resistance to thiambutosine in the poor absorber of the drug (Patient $6280 / 51)$. From evidence not presented here, there was also some suggestion of the emergence of resistance in at least 2 of the other 20 patients who had been treated for over 2 years with thiambutosine. These clinical and bacteriological results confirm the previous findings of Davey (1960). Since our studies were concluded, Rees $(1965,1967 \mathrm{a}, 1967 \mathrm{~b})$ has inoculated mice with strains of $M$. leprae from patients who had been treated with thiambutosine for 2 or more years, and from patients who had relapsed while taking thiambutosine. He reported that a much lower proportion of the resultant foot-pad infections were inhibited by thiambutosine than were infections from untreated patients. The appearance of resistance to thiacetazone in $M$. leprae was suggested by Lowe (1954). He concluded that despite the initial effectiveness of thiacetazone, after 2 or more years treatment a considerable proportion of patients reached a stage where the drug seemed to lose its action and further progress was not seen. Moreover, in several patients there was definite clinical and bacteriological regression.

A chronic infection where the limitations of treatment with a single drug are well documented is pulmonary tuberculosis. The emergence of resistant strains of $M$. tuberculosis can readily be demonstrated by sensitivity tests on sputum cultures. The fundamental bacteriological reasons for the successful treatment of tuberculosis with combinations of 2 or 3 drugs and the comparative failure of 'mono-therapy' have recently been discussed by Mitchison (1965). In tuberculosis, the large population of bacilli in an untreated patient infected with a 'sensitive' strain of $M$. tuberculosis contains a small number of mutants of varying degrees of resistance to the drugs employed in chemotherapy. Presumably a similar situation occurs in leprosy. Mutants with high degrees of resistance are probably rarer than those with low degrees of resistance. When tuberculosis is 
treated with isoniazid alone, raising the dose of isoniazid from 100 through 200 to $400 \mathrm{mgm}$. resulted in increased inhibition of the growth of mutants of low degrees of isoniazid resistance (Selkon et al., 1964) and at the same time improved therapeutic effectiveness (Tuberculosis Chemotherapy Centre, Madras, 1960).

In contrast, DDS has been used very successfully without other drugs for the treatment of leprosy, and the appearance of strains of $M$. leprae resistant to the concentrations of DDS obtained in the body after dosage with $300 \mathrm{mgm}$. DDS twice weekly, is very rare (Pettit and Rees, 1964; Pettit, Rees and Ridley, 1966). The reason for this somewhat surprising finding appears to be that $M$. leprae is inhibited by very low concentrations of DDS. The concentrations of DDS obtained in the body, when doses of the order of $100 \mathrm{mgm}$. a day are given, are probably 100 or even 1,000 times greater than the concentration of DDS required to inhibit the growth of $M$. leprae (Shepard, McRae and Habas, 1966; Rees, 1967a, 1967b). Mutants of $M$. leprae capable of growing at the DDS concentrations in the body are likely to be very rare and may even be absent in many patients.

Nothing is known concerning the concentration of thiambutosine (and/or its metabolites) necessary to inhibit the growth of $M$. leprae. An increase in the dose of thiambutosine does not increase the amount of drug absorbed (Ellard, 1961), and so could not be expected to reduce or delay the appearance of resistance to thiambutosine. There is some evidence, however, suggesting that twice daily treatment with thiambutosine, which doubles the amount of drug absorbed each day (Ellard, 1961), may delay the emergence of resistance (East African Leprosy Research Centre, 1960).

Adams and Waters (1966) have demonstrated the cross-resistance of a DDS-resistant strain of $M$. leprae to a long-acting sulphonamide, but not to thiacetazone or thiambutosine; and Rees (1967a) has demonstrated the crossresistance of thiambutosine-resistant strains of $M$. leprae to thiacetazone. It is therefore anticipated that just as patients with DDS- resistant leprosy responded satisfactorily to treatment with the rimino-phenazine derivative B663 (Pettit and Rees, 1966), so patients who have relapsed during prolonged treatment with thiambutosine should respond satisfactorily to treatment with DDS or B663. In our studies patients were transferred to treatment with DDS and appeared to respond normally.

It was concluded that the poor response of one of the patients $(6280 / 51)$ to treatment with thiambutosine was probably due to his absorbing an unusually small amount of the drug. The reasons behind this rather uncommon phenomenon are not understood.

\section{SUMMARY}

1. Clinical and bacteriological evidence is presented suggesting the appearance of resistance to thiambutosine in 3 patients from a group of 23 patients who had been treated with the drug for between 24 and 45 months.

2. Biochemical studies showed that 2 of these 3 patients absorbed the drug normally, but that the other patient absorbed an unusually small proportion of the dose.

3. Resistance to thiambutosine developed after 28 and 44 months, respectively, in the 2 patients who absorbed the drug normally.

4. It is therefore concluded that although thiambutosine has a useful role to play in the treatment of leprosy it would seem unwise to continue treatment with the drug for more than 2 years.

\section{ACKNOWLEDGEMENTS}

We should like to thank Dr. R. J. W. Rees and Professor D. A. Mitchison for helpful advice during the preparation of this paper, and the Secretary General, East African Community, for permission to publish. Our thanks are also due to the British Leprosy Relief Association for financial assistance, and to CIBA Ltd. for generous supplies of thiambutosine.

\section{REFERENCES}

ADAms, A. R. D. and WAters, M. F. R. (1966). Dapsone resistant lepromatous leprosy in England. Brit. med. .J., 2, 872 . 
DAVEY, T. F. (1960). Some recent chemotherapeutic work in leprosy. Trans. Roy. Soc. Trop. Med. Hyg., 54, 199.

DAVEY, T. F., et al. (1958). The treatment of leprosy with the diphenyl thiourea compound SU 1906 (DPT). Lep. Rev., 29, 25.

EAST AFRICAN LEPROSY RESEARCH CENTRE (1960). Annual Report, 1959/1960. East Africa High Commission, Nairobi.

ELlARD, G. A. (1961). The absorption, metabolism and excretion of l-(p-dimethylaminophenyl)-3(p-butoxyphenyl)-2-thiourea in man. Part 1. A study using colorimetric methods. Lep. Rev., 32, 233.

Ellard, G. A. and NAYlor, R. F. (1961). Ibid, Part 2. A study using ${ }^{35} \mathrm{~S}$-labelled drug. Lep. Rev., 32, 249.

ELlARD, G. A. (1966). A preliminary study of the absorption, metabolism and excretion of injectable thiambutosine. Lep. Rev., 37, 17.

GARROD, J. M. B. (1959). Two years experience with diphenylthiourea (DPT or CIBA 1906) in the treatment of leprosy. Lep. Rev., 30, 210.

LowE, J. (1954). The treatment of leprosy with TBl/698. Lep. Rev., 25, 186.

Mitchison, D. A. (1965). Chemotherapy of tuberculosis: a Bacteriologist's viewpoint. Brit. med. J., 1, 1333.

PETTIT, J. H. S. and REES, R. J. W. (1964). Sulphone resistance in leprosy. Lancet, 2, 673.

PETtit, J. H. S. and ReEs, R. J. W. (1966). Studies in sulfone resistance in leprosy. 2. Treatment with a riminophenazine derivative (B663). Int. J. Lepr., 34, 391 .
PETTit, J. H. S., REES, R. J. W. and RIDLEY, D. S. (1966). Studies in sulfone resistance in leprosy. 1. Detection of cases. Int. J. Lepr., 34, 375.

REES, R. J. W. (1965). Recent bacteriologic, immunologic and pathologic studies on experimental human leprosy in the mouse foot pad. Int. J. Lepr., 33, 646.

REES, R. J. W. (1967a). Leprosy. A preliminary review of the experimontal evaluation of the drugs for the treatmont of leprosy. Trans. Roy. Soc. Trop. Med. Hyg., 61, 581 .

REES, R. J. W. (1967b). Drug resistance of Mycobacterium leprae, particularly to DDS. Int. J. Lepr., 35,625 .

RIDLEY, D. S. (1958). Therapeutic trials in leprosy using serial biopsies. Lep. Rev., 29, 45.

SElKON, J. B., DEVADATTA, S., KULKARNI, K. G., MITCHISON, D. A., NARAYANA, A. S. L., NAIR, C. N. and RAMACHANDRAN, K. (1964). The emergence of isoniazid-resistant cultures in patients with pulmonary tuberculosis during treatment with isoniazid alone or isoniazid plus PAS. Bull. Wld. Hlth. Org., $31,273$.

SHEPARD, C. C., MCRAE, D. H. and HABAS, J. A. (1966). Sensitivity of Mycobacterium leprae to low levels of 4, 4'-Diaminodiphenyl Sulfone. Proc. Soc. Exper. Biol. Med., 122, 893.

TUBERCULOSIS CHEMOTHERAPY CENTRE, MADRAS (1960). Concurrent comparison of isoniazid plus PAS with three regimens of isoniazid alone in the domiciliary treatment of pulmonary tuberculosis in South India. Bull. Wld. Hlth. Org., 23, 535. 